\title{
A Double Carbon-Carbon Bond Activation of 8-Quinolinyl Cyclopropyl Ketone by Chlorobis(ethylene)rhodium(I) Dimer
}

\author{
Dae-Yon Lee and Chul-Ho Jun \\ Deparment of Chemistry, Fonsei Lniversitw, Seoul 120-749, Korea \\ Received Mav 31, 2003
}

Key Words : C-C bond activation. Ketone. Rhodium. Quinoline. Cyclopropyl

The activation of $\mathrm{C}-\mathrm{C}$ bonds in organic molecules is one of current interests in organometallic chemistry especially due to its potential utility in sy'nthetic method to form carbon skeleton. and a number of strategies have been devised in order to cleave C-C bond. ${ }^{3}$ Among those strategies. it is the most common way to utilize the relief of ring strain energy' of strained molecules such as cyclopropane cyclobutane. and their derivatives. ${ }^{2}$ Recently. a chelation-assistance protocol utilizing cyclometalation was developed to be regarded as one of the most promising ways as it could solve a problem concerning accessibility of metal complexes toward a C-C bond to be cleaved. ${ }^{3}$ Quinoline derivatives are frequently used as cyclometalation models because they form very stable metal complexes. ${ }^{4}$ and many preparation methods of quinolines are known. In the course of our studies on a chelation-assisted $\mathrm{C}-\mathrm{C}$ bond activation using 8-quinoliny 1 alkyl ketones. in which the C-C bond $\alpha$ to the carbonyl group could be easily cleaved by transition metal complexes. ${ }^{+}$ we envisaged that a double $\mathrm{C}-\mathrm{C}$ bond activation could be achieved when 8-quinolinyl alkyl ketone bearing a strained substituent such as cyclopropyl group was used as a substrate. In this communication, we wish to explain a consecutive chelation-assisted activation of the $\mathrm{C}-\mathrm{C}$ bond $\alpha$ to the carbonyl group and a ring opening of cyclopropyl group using 8-quinolinỵl cyclopropyl ketone

In our experiment, cylcopropyl quinolin-8-yl methanone $(1)^{6}$ was allowed to react with a suspension of chlorobis(ethylene)rhodium(I) dimer (2) in benzene at $100^{\circ} \mathrm{C}$ for 1.5 h to give a dark brown precipitate. Since it was hard to isolate and identify the resulting reaction mixture due to complicated spectral data, the structures of these complexes were identified by those of ketones obtained through a ligand-promoted reductive elimination by pyridine and $\mathrm{P}(\mathrm{OMe})_{3}$.

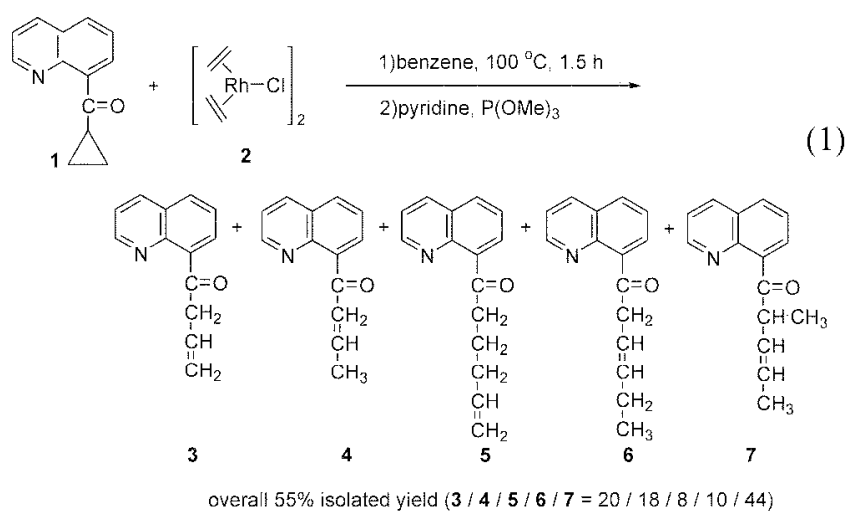

After the reductive elimination. a mixture of (1-quinolin-8yl)-but-3-en-1-one (3). (1-quinolin-8-yl)-but-2-en-1-one (4). (1-quinolin-8-yl)-hex-5-en-1-one (5). (1-quinolin-8-yl)-hex3-en-1-one (6). and 2-methyl-(1-quinolin-8-yl)-pent-3-en-1one $(7)^{7}$ was obtained in a $55 \%$ isolated yield with a ratio of $20: 18: 8: 10: 4$ by colunn chromatographic isolation (eq. 1).

Among the products. 8-quinolinyl propenyl ketones. 3 and 4. are derived from the ring opening of cyclopropyl group. and 8-quinolinyl pentenyl ketones. 5. 6. and 7. are formed though the insertion of the ethylene into $\pi$-allylrhodium intermediate followed by isomerization.

Monitoring the ratio of products along the reaction revealed that the amount of 8-quinolinyl propenyl ketones ( 3 and 4) decreased while that of 8-quinolinyl pentenyl ketones (5-7) increased. Especially: the amount of 7 increased as reaction proceeded and was the sole product after $48 \mathrm{~h}$ (Table 1). This result implies that precursor complexes of ketone 3 and 4 are the initial products. and then transform into those of 5, 6. and 7 as reaction proceeds.

A plausible mechanism for the reaction is depicted in Scheme 1 .

The first step of the reaction might be a chelation-assisted activation of the C-C bond $\alpha$ to the carbonyl group in $\mathbf{1}$ by $\mathbf{2}$ to give an acylrhodium(III) cyclopropyl complex 8 . Further ring opening of cyclopropyl group ${ }^{2}$ in $\mathbf{8}$ generates an acylrhodium(III) $\pi$-allyl complex $\mathbf{9}$, which gives 3 after the reductive elimination. This $\beta, \gamma$ unsaurated ketone $\mathbf{3}$ is so unstable that the terminal olefin is easily isomerized into internal olefin to afford the $\alpha \beta$-unsaturated isomer 4 during the reductive-elimination and/or cluromatographic isolation

Table 1. The Reaction Profile for the C-C. Bond Activation of 8 Quinolinyl Cyclopropyl Ketone (1) by Chlorobis(ethylene rho$\operatorname{dilum}(\mathrm{I}) \operatorname{Dimer}(2)^{a}$

\begin{tabular}{|c|c|c|c|c|c|c|c|}
\hline \multirow{2}{*}{ Entry } & \multirow{2}{*}{$\begin{array}{l}\text { Reaction } \\
\text { time (h) }\end{array}$} & \multicolumn{5}{|c|}{ Ratio of products ${ }^{b}$} & \multirow{2}{*}{$\begin{array}{l}\text { Isolated yield } \\
\text { of products }(\%)\end{array}$} \\
\hline & & 3 & 4 & 5 & 6 & 7 & \\
\hline 1 & 1.5 & 20 & 18 & 8 & 10 & 44 & 55 \\
\hline 2 & 3 & 11 & 16 & 7 & 9 & 57 & 62 \\
\hline 3 & 6 & 5 & 19 & 9 & 9 & 59 & 66 \\
\hline 4 & 12 & 4 & 13 & 6 & 7 & 70 & 50 \\
\hline 5 & 24 & 0 & 6 & 4 & 9 & 82 & 42 \\
\hline 6 & 48 & 0 & 0 & 0 & 0 & 100 & 38 \\
\hline
\end{tabular}

The reaction was carried out in benzene at $100^{\circ} \mathrm{C}$, and then pyridine and $\mathrm{P}(\mathrm{OMe})$ was added for a reductive elimination. 'The ratio was determined by ${ }^{1} H$ NMR after chromatographic isolation. 


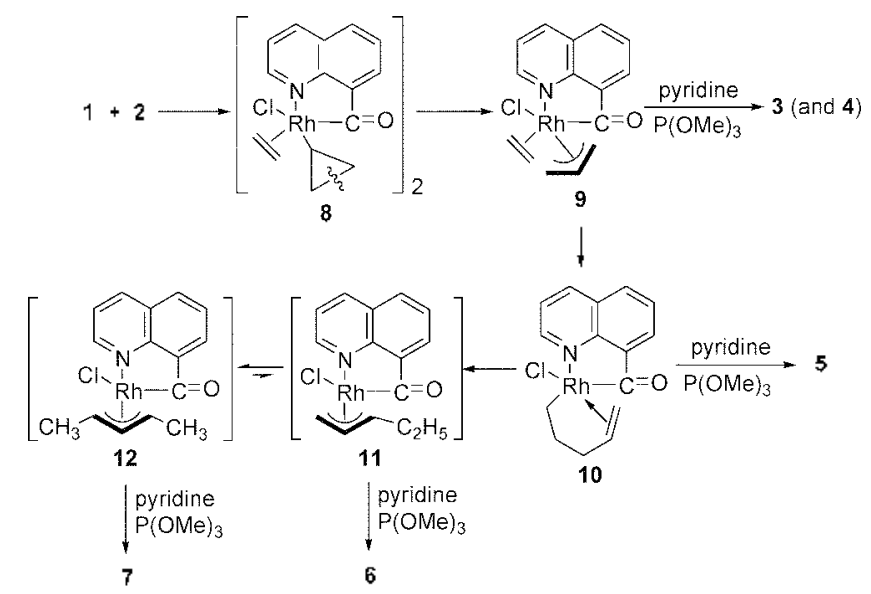

Scheme 1. A proposed mechanism of the reaction of 8-quinolinyl cyclopropyl ketone (1) and $\left[\left(\mathrm{C}_{2} \mathrm{H}_{4}\right)_{2} \mathrm{RhCl}\right]_{2}(2)$.

processes. It is also possible that $\beta$-hydrogen elimination in $\mathbf{8}$ proceeds to form cyclopropene and acylrhodium(III) hydride, in which circuntstance 8-quinolinyl ethyl ketone should be generated through an insertion of the coordinated etlylene and the reductive elimination. ${ }^{s}$ However. 8-quinolinyl ethyl ketone was not observed. and it implies that $\beta$-hydrogen elimination in $\mathbf{8}$ does not take place because the formation of highly strained cyclopropene is not favored. A migratory insertion of the coordinated ethylene into acylrhodium(III) $\pi$-allyl complex 9 leads to the acylrhodium(III) 4 -pentenyl complex 10a, which undergoes the reductive elinination to give 5. There are very few exanples of intermolecular insertion of olefin into the $\pi$-allyl-metal moiety while this process is assumed as a key step in dimerization. oligomerizaiton or polymerization of diene. ${ }^{10}$ The complex $10 \mathrm{a}$ is easily transformed into a stable acylrhodium(III) $\eta \hat{j}$ - I-ethylallyl conplex 11. which is further isomerized to more stable acylrhodium(III) $\eta^{3}-1.3$-dimethylallyl complex 12 . It was already reported that complex 11 is a kinetic product. and complex 12 is a thermodynamic product in the reaction of 8-quinolinecarboxaldehyde and chlorobis(1.4-pentadiene)rhodium(I) complex ${ }^{\text {ta }}$ A ligand-promoted reductive elimination of complex 11 and 12 produces the corresponding ketone 6 and 7. respectively:

In conclusion, a double $\mathrm{C}-\mathrm{C}$ bond activation of 8-quinolinyl cyclopropỵl ketone. a consecutive chelation-assisted activation of the $\mathrm{C}-\mathrm{C}$ bond $\alpha$ to the carbonyl group and the ring opening of cyclopropyl group. was achieved by chlorobis(ethylene)rhodium(I) dimer. An insertion of the coordinated ethylene into the resulting acylrhodium $\pi$-allyl complex afforded 8-quinolinyl pentenyl ketones through the subsequent isomerization.

Acknowlegement. This work was supported by Korean Science and Engineering Foundation (20004010). Authors thank the Korean Basic Science Institute for obtaining HRMS data.

\section{References}

1. For reviews, see: (a) Crabtree. R. H. Chem. Rev: 1985. 85. 245. (b) Rrbtchinski. B.: Milstein. D. Arrgen. (Them. Iht Ed. 1999. 38, 870. (c) Jennings, P. W. Johnson. L. L. Chem. Ren. 1999, 94, 2241. (d) Murakani, M.: Ito. Y. In Activation of Linteactive Bonds and Organic
Swhthesis. Murai, S., Ed.; Springer: Berlin, German. 1999: pp 97-129.

2. (a) Bishop. K. C. Chem. Rev: 1976. 76. 461. (b) Periana. P. A.: Bergman. R. G. J. Aim. Chent Soc. 1984. 106.7272. (c) Murakani. M: Ami. H.: Ito. Y. Nattre 1994. 370.540. (d) Edelbach. B. L.: Lachicotte. R. J.; Jones, W. D. J.Am. Chem. Soc. $1998,120,2843$. (e) Nishimura. T: Uemura. S. J. Am. Chem. Soc. 1999, 121. 11010 . (f) Murakani, M.: Tsuruta, T.: Ito. Y. Angen. Chent. Int. Ed. 2000. 39,2484.

3. (a) Bruce. M. I. Angew. Chem., Int. Ed Engt 1977. 16. 73. (b) Ryabov. A. D. Chent Rer: 1990. 90. 403. (c) Tun. C.-H.: Hong. T.B.: Lee. D.-Y. Synlett 1999. 1. (d) Jun. C.-H.: Moot1. C. W.: Lee. D.-Y. Chem. Ew: J. 2002.8,2423.

4. (a) Jun, C.-H. J. Organonet. Chem 1990, 390. 361. (b) Jun. C.H. Kang. J.-B.: Lim. Y.-G.. Tetrahedron Lett. 1995. 36. 277. (c) Jur1. C.-H. Organometallics 1996. 15.895. (d) Lee. D.-Y.: Lim. Y.G.: Ju11. C.-H. Bull. Koreon Chent. Soc. 1997. 18. 824.

5. (a) Joule. J. A.: Mills. K.: Smiths. G. F. Heterocychic Chemisoy. 3rd ed. Chapman \& Hall: London. UT. K., 1972: pp 1201-145. (b) Suggs. J. W: Pearson, G. D. J. Org Chem 1980. 45. 1514. (c) Cho. C. S.; Kim. T. K.: Choi, H.-J.: Shim, S. C. Bull. Konew Chent Soc. 2002. 23. 541 . (d) Kim. I. N.: Lee. K. Y.: Ham. H.-S.: Kimn. H. R.: Ryu. E. K. Bull. Korean Chent. Soc. 2001. 22. 135.

6. Compound 1 was prepared from the reaction of cyclopropanecarbosaldehyde and 8-lithio quinoline derived from sec-but:l lithium and 8-bromoquinoline. followed by Swern oxidation of resulting alcohol. 1: ${ }^{1} \mathrm{H}$ NMR (250 MHz, CDCls): $\delta$ (ppm) 8.98 (dd. $J=4.2 .1 .7 \mathrm{~Hz} .1 \mathrm{H}$ ). 8.17 (dd. $J=8.3 .1 .7 \mathrm{~Hz} .1 \mathrm{H}$ ). $7.89(\mathrm{~m}$. 2H). $7.55(\mathrm{~m} . \mathrm{lH}) .7 .42(\mathrm{~m} . \mathrm{lH}) .3 .57(\mathrm{~m} 1 \mathrm{lH}) .2 .98(\mathrm{~m} . \mathrm{lH}) .1 .39$ (m. $2 \mathrm{H}) .1 .10(\mathrm{~m} .2 \mathrm{H}):{ }^{13} \mathrm{C} \mathrm{NMR}\left(62.9 \mathrm{MHz} . \mathrm{CDCl}_{3}\right): \delta(\mathrm{ppm})$ $206.7(\mathrm{CO}) .151 .1-121.8$ (Cs of quinoline ring). $23.6(\alpha$-carbon to CO). 13.2 ( $\beta$-carbons to $C O$ ): IR (neat): $3074,3006.1675,1574$. 1497. $1447,1380,1253,1059.970 .830,803,767 \mathrm{~cm}^{-1}$, MS mz (0. relative intensity): $197\left(13.2 . \mathrm{M}^{+}\right) .169(\mathrm{I}(00) .156(9.7) .128(21)$ : HRMS (EI) $n z z$ : calcd for $\mathrm{C}_{13} \mathrm{H}_{11} \mathrm{NO}$ 197.079594. found 197.0794 I l.

7. A typical prodedure (eq. 1): A screw-capped pressure vial ( $3 \mathrm{~mL}$ ) was charged with $20.0 \mathrm{mg}(0.0102 \mathrm{mmol})$ of $1,19.7 \mathrm{mg}(0.058$ mmol) of 2 , and $2 \mathrm{~mL}$ of benzene. The reaction mixture was stirred for $1.5 \mathrm{~h}$ in an oil bath preheated to $100^{\circ} \mathrm{C}$. After the reaction, the mixture was cooled to room temperature. and $150 \mathrm{mg}$ of pyridine and $120 \mathrm{mg}$ of $\mathrm{P}(\mathrm{OMe})$ s were added. After stirred for overnight. the reaction mixture was purified by column chromatography $\left(\mathrm{SiO}_{2}, n\right.$-hexane : ethyl acetate $\left.=5: 2\right)$ to afford $12.0 \mathrm{mg}\left(55^{\circ} \mathrm{o}\right)$ of a misture of 8 -quinolinyl alkenyl ketones $3,4,5.6$, and 7 in a ratio of $20: 18: 8: 10: 44$ (determined by ${ }^{1} \mathrm{H}$ NMR). Among the products. 3 was inseparable as it is readily isomerized to more stable 4 during isolation processes. Therefore. compound 3 was identified by ${ }^{1} \mathrm{H}$ NMR and GC-MS. 3: ${ }^{1} \mathrm{H}$ NMR $(250 \mathrm{MHz}$. $\left.\mathrm{CDCl}_{3}\right) \delta(\mathrm{ppm}): 8.98(\mathrm{dd}, J=4.2 .1 .7 \mathrm{~Hz}, 1 \mathrm{H}), 8.17(\mathrm{dd}, J=8.3$. $1.7 \mathrm{~Hz} .1 \mathrm{H}) .7 .89(\mathrm{~m} .2 \mathrm{H}) .7 .55(\mathrm{~m}, 1 \mathrm{H}), 7.42(\mathrm{~m}, 1 \mathrm{H}), 6.12(\mathrm{~m}$. lH). $5.18(\mathrm{~m}, 2 \mathrm{H}), 4.20(\mathrm{~d}, J=6.9 \mathrm{~Hz}, 2 \mathrm{H}): \mathrm{MS} \mathrm{mz}$ ("w relative intensity): 197 (6.9. M-). 182 (78.4). 169 (100). 156 (29.1). 154 (42.9). 128 (38.4) 4. ' $\mathrm{H}$ NMR (250 MHz. CDCl $) \delta(\mathrm{ppm})$ ): 8.98 (dd. $J=4.2 .1 .7 \mathrm{~Hz} .1 \mathrm{H}$ ). 8.17 (dd. $J=8.3 .1 .7 \mathrm{~Hz} .1 \mathrm{H}$ ). 7.89 (m. 2H). $7.55(\mathrm{~m}, \mathrm{lH}) .7 .42(\mathrm{~m}, 1 \mathrm{H}), 6.80(\mathrm{~m} .2 \mathrm{H}) .1 .95(\mathrm{~m}, 3 \mathrm{H}):{ }^{13} \mathrm{C}$ NMR $\left(62.9 \mathrm{MHz}, \mathrm{CDCl}_{3}\right) \delta(\mathrm{ppm}): 196.5(\mathrm{CO}) .150 .7-121.5(\mathrm{Cs}$ of quinoline ring and $\alpha \beta$-carbons to $\mathrm{CO}), 18.6\left(\mathrm{CH}_{3}\right)$ : IR (neat): 2906.2927 .2869 . 1726. 1662. 1621. 1572. 1 446. 1382. 1285.1128. I $071.967 .826 .796 \mathrm{~cm}^{-1}$ : MS $n$ z (\%o relative intensity): 197 (3.2. $\left.\mathrm{M}^{+}\right) .182$ (100). 168 (25). 156 (16). 154 (34.8). 128 (21.5). Other products, 5, 6. and 7 have already been reported (see ref. $4(a)$ ).

8. Suggs. J. W. Jun. C.-H. J. Chen. Soc., Chem. Commun 1985, 92.

9. (a) Meching. S.: Keim. W. Organonetallics 1996. 15. 2650. (b) DiRerizo. G. M.: White. P. S.: Brookhart. M. J. Am. Chent Soc. 1996. 118.6225.

10. (a) Tolman. C. A. J.Am Chem. Soc 1970. 92.6785. (b) Bray. K. L.: Charmant, J. P. H.: Fairlamb, I. J. S.; Lloyd-Jones. G. C. Chem Ew: J. 2001, 7,4205. (c) Deckers, P. J. W.; Hessen, B; Teuben, J. H. Angan: Chent Int Ed 2001, t0, 2516. (d) Cárdenas, D. J. Alcami, M Cossío. F.: Méndez. M.: Echavarren. A. M. Chem. Eum J. 2003. 9.96. 